\title{
Microgram per Liter
}

National Cancer Institute

\section{Source}

National Cancer Institute. Microgram per Liter. NCI Thesaurus. Code C67306.

A unit of mass concentration defined as the concentration of one microgram of a substance per unit volume of the mixture equal to one liter. The concept also refers to the unit of mass density (volumetric mass) defined as the density of a substance which mass equal to one microgram occupies the volume of one liter. 